Weaver, G. M., N. Smith, E. B. Berndt, K. D. White, J. F. Dostalek, and B. T. Zadovsky, 2019: Addressing the cold air aloft aviation challenge with satellite sounding observations. J. Operational Meteor., 7 (10), 138-152, doi: https://doi.org/10.15191/nwajom.2019.0710

Journal of Operational Meteorology
Article

\title{
Addressing the Cold Air Aloft Aviation Challenge with Satellite Sounding Observations
}

\author{
GAIL M. WEAVER \\ NOAA/NWS Anchorage Center Weather Service Unit, Anchorage, Alaska \\ NADIA SMITH \\ Science and Technology Corporation, Columbia, Maryland \\ EMILY B. BERNDT \\ NASA Marshall Space Flight Center, Short-term Prediction Research and Transition Center, Huntsville, Alabama \\ KRISTOPHER D. WHITE \\ NASA Marshall Space Flight Center, Short-term Prediction Research and Transition Center, Huntsville, Alabama \\ NOAA/NWS, Huntsville, Alabama \\ JOHN F. DOSTALEK \\ Cooperative Institute for Research in the Atmosphere, Colorado State University, Fort Collins, Colorado \\ BRADLEY T. ZAVODSKY \\ NASA Marshall Space Flight Center, Huntsville, Alabama
}

(Manuscript received 15 January 2019; review completed 14 June 2019)

\begin{abstract}
At high latitudes in winter, the atmosphere at flight levels used by passenger and cargo aircraft can reach temperatures cold enough to restrict the flow of jet fuel from the fuel tanks to the engine, due either to water freezing in the fuel or the fuel itself freezing. Currently, aviation forecasters rely on a combination of aircraft reports, pilot reports, a sparse network of radiosondes, and global model fields for identifying and characterizing Cold Air Aloft (CAA) events. More atmospheric data are needed to improve forecasts of CAA placement and timing, and satellite observations can help fill the gap. In particular, products derived from the NOAA-Unique Combined Atmospheric Processing System (NUCAPS) can be utilized by National Weather Service (NWS) forecasters to assist in the production of aviation hazard products. NUCAPS combines measurements from infrared and microwave sounding instruments on polar-orbiting satellites to retrieve atmospheric profiles of temperature and moisture in the high latitudes. NWS forecasters have real-time access to NUCAPS soundings via the Advanced Weather Interactive Processing System-II (AWIPS-II). The Joint Polar Satellite System Sounding Applications Initiative created Gridded NUCAPS in order to view soundings as isobaric surfaces or vertical cross sections in AWIPS-II. The Cooperative Institute for Research in the Atmosphere (CIRA) developed a web-based product for displaying satellite-derived CAA information. This paper describes how the AWIPS-II and CIRA displays of satellite sounding observations augment aviation forecasting activities in Alaska using two specific CAA cases from the 2016-2017 and 2017-2018 winter seasons.
\end{abstract}

\section{Introduction}

The vast majority of commercial planes fly between $9144 \mathrm{~m}(30000 \mathrm{ft})$ and $12192 \mathrm{~m}(40000 \mathrm{ft})$, which equates to heavy air traffic at or just below the tropopause in the northern high latitudes. At the tropopause, the atmospheric temperature reaches a minimum, routinely falling below $-65^{\circ} \mathrm{C}$ in the winter months. Even though

Corresponding author address: Gail M. Weaver, ZAN Center Weather Service Unit, Anchorage, AK 99506

E-mail: gail.weaver@noaa.gov 


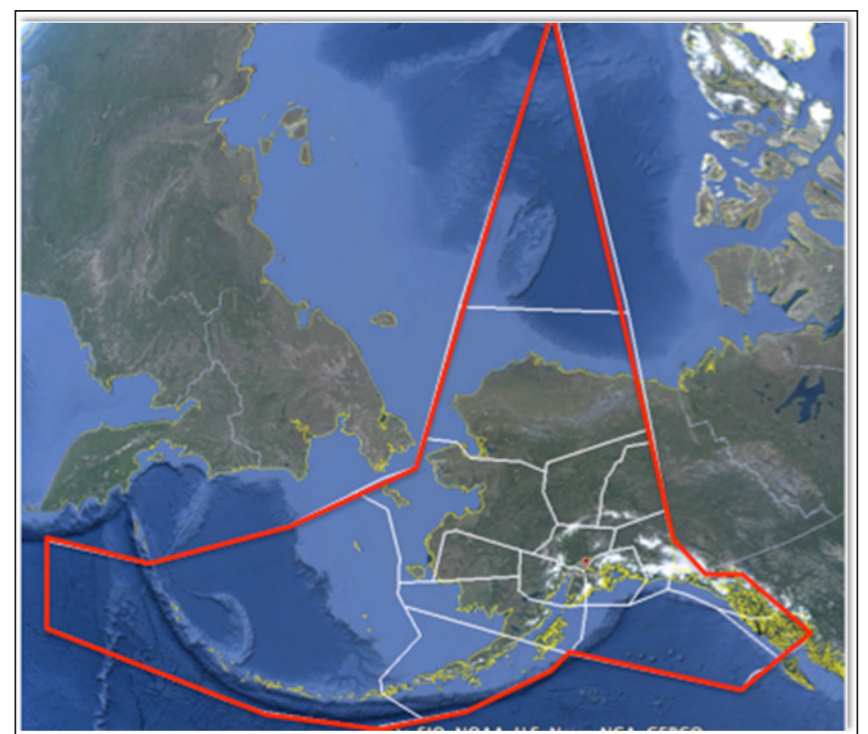

Figure 1. The Anchorage CWSU forecast area of responsibility outlined in red. Click image for an external version; this applies to all figures hereafter.

Cold Air Aloft (CAA) areas occur in all latitudes, they are considered a flight risk only in the higher latitudes because the lower tropopause height in these regions

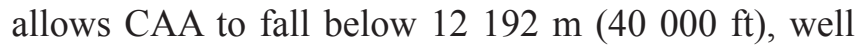
within the commercial flight zone. In the tropics, CAA can be observed at $12326 \mathrm{~m}$ (47 $000 \mathrm{ft}$ ) or higher, but this is well beyond the area of interest for commercial air traffic control.

When flying for extended periods in cold conditions, the effect of the outside air temperature on the fuel becomes a concern. The problem either can be the result of any water in the fuel tanks or the fuel itself beginning to freeze. Freezing of jet fuel is not the formation of a solid as such, but rather the formation of wax crystals, which increase in amount as the temperature of the fuel decreases. Different kinds of jet fuel freeze at different temperatures, but the jet fuel most commonly used in the United States, Jet-A, begins to form wax crystals at $-40^{\circ} \mathrm{C}$ (Bachtel et al. 2001). Typically, the formation of ice crystals occurs at a higher temperature than the formation of the fuel wax crystals. An excessive amount of either ice crystals or wax crystals can restrict the flow of fuel from the tanks to the engines. On 17 January 2008, a Boeing 777 operated by British Airways crashed at London's Heathrow Airport as it completed its flight from Beijing, China. Luckily, all the passengers survived the crash. According to the United Kingdom's Air Accidents Investigation Branch, the accident was due to engine failure caused by ice formation from water occurring naturally in the fuel
FAAK20 KZAN 082312

ZAN MIS 01 VALID 082312-090600

...FOR ATC PLANNING PURPOSES ONLY...

FROM 575NNW BRW-510NNE BRW-175NE SCC-BRW-200W BRW-572N BRW COLD AIR ALOFT

TEMPS -65C OR LESS FM FL310-FL340. MOV E 15 KT. INTSF.

GMW DEC 16

Figure 2. An example of an Anchorage CWSU CAA MIS. The MIS includes information about CAA horizontal (line 4) and vertical extent (line 6), as well as movement and intensity change (line 6).

(Sleight and Carter 2010). According to Lacagnina (2010), the lowest outside air temperature recorded during the flight was $-74^{\circ} \mathrm{C}$.

In order to monitor aircraft flights over the United States, the Federal Aviation Administration (FAA) operates 21 air route traffic control centers (ARTCC). The Anchorage Center Weather Service Unit (CWSU) is co-located with the Anchorage ARTCC and provides aviation hazard forecasts for airspace that covers 6.2 million sq $\mathrm{km}$ (2.4 million sq mi), stretching from the North Pole to the Russia, Japan, Canada, and Oakland, California, Flight Information Regions (Fig. 1). Not only is the Anchorage ARTCC airspace the northernmost FAA air traffic control region, it is also one of the busiest worldwide for both cargo and passenger air traffic.

The Anchorage CWSU produces two aviation hazard products to support safe and efficient air travel across Alaska airspace: The Center Weather Advisory (CWA) and the Meteorological Impact Statement (MIS). The CWA is a short-term warning - typically valid for up to $2 \mathrm{~h}$-issued for real-time hazardous conditions, such as low-level wind shear, turbulence, icing, volcanic ash, and embedded thunderstorms. The MIS is issued for hazards lasting longer than $2 \mathrm{~h}$ and is valid for up to $12 \mathrm{~h}$ to allow for flight planning ahead of passage through Alaska airspace. One hazard covered by the MIS is CAA, and the Anchorage CWSU uses $-65^{\circ} \mathrm{C}$ as the threshold for issuing a CAA MIS. An example MIS for a CAA event is shown in Fig. 2.

Of all the FAA air traffic control centers, the Anchorage CWSU is the only one that issues MISs for CAA events. CWSU forecasters need to provide pilots and air traffic controllers with information on the full three-dimensional (3-D) extent of the CAA event including identification of atmospheric temperature locations less than $-65^{\circ} \mathrm{C}$, vertical and horizontal extent, temporal onset, duration, movement, and intensity. In the example provided in Fig. 2, the CAA horizontal extent is described by using $\mathrm{n}$ mi distances from airport navigational aids; the CAA vertical extent 


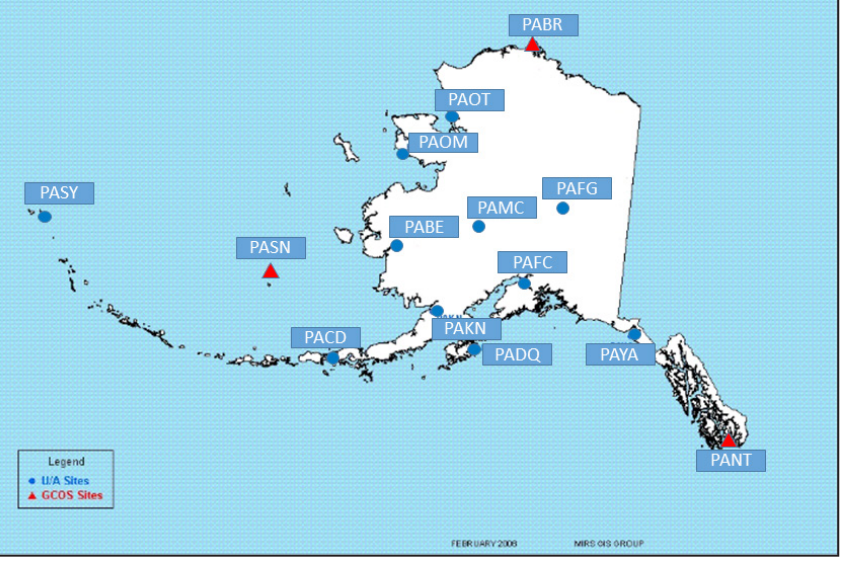

Figure 3. AK upper-air (U/A) network. Three stations (PASN, PABR, and PANT) also are designated as Global Climate Observing System (GCOS) Sites.

is outlined using flight levels in thousands of $\mathrm{ft}$ above mean sea level; the CAA movement is defined using the direction and speed (kt) in which the CAA is moving; and the CAA intensity level is described as intensifying (INTSF), no change (NC), or weakening (WKN).

Accurate forecasts of CAA events are often hampered by the lack of observations. For the 6.2 million sq $\mathrm{km}$ (2.4 million $\mathrm{sq} \mathrm{mi}$ ) for which the Anchorage CWSU has forecast responsibility, there are only 14 stations that launch radiosondes (Fig. 3), and many times soundings are not available because of staffing shortages, equipment malfunctions, or computer/network issues. The lack of observations further compounds the forecast challenge by impacting the quality of Numerical Weather Prediction (NWP) models that strongly depend on observations to offset model biases. It is for this reason that forecast models are often associated with high uncertainty in remote regions such as Alaska. Forecasters thus need other sources of observations, not only to make assessments of specific phenomena, but also to improve NWP analyses and verify model forecasts. The National Oceanic and Atmospheric Administration (NOAA) Unique Combined Atmospheric Processing System (NUCAPS) (Susskind et al. 2003; Gambacorta 2013; Gambacorta and Barnet 2013; Gambacorta et al. 2017) fills the observational gap by providing hundreds of Skew-T diagrams in the Advanced Weather Interactive Processing System-II (AWIPS-II), the National Weather Service's (NWS) operational decision support software. NUCAPS uses the Cross-track Infrared Sounder (CrIS) and Advanced Technology Microwave Sounder (ATMS) on polar-orbiting satellites [e.g., Suomi National Polarorbiting Partnership (S-NPP) and NOAA-20] to produce swaths of high-quality temperature and moisture profiles. Additionally, the ability to view soundings as isobaric surfaces or vertical cross sections in AWIPS-II was developed through a Joint Polar Satellite System (JPSS) Program Sounding Applications Initiative. This Gridded NUCAPS capability enables visualization of the full spatial and vertical extent of CAA features to supplement the sparse radiosonde network and decrease model forecast uncertainty.

This paper gives an account of the innovative solution that meteorologists at the Anchorage CWSU advanced to overcome their observational challenges. Together with satellite product developers from the JPSS Proving Ground and Risk Reduction (PGRR) Program Sounding Initiative, they designed an information product that uses satellite sounding observations to supply aviation meteorologists with simple, accurate, and readily accessible information to recognize CAA events. Section 2 provides a description of satellitebased NUCAPS products that aviation meteorologists use to produce CAA MIS operational products, and section 3 explains how the Anchorage CWSU used winter assessments to validate NUCAPS data for operational use. Section 4 summarizes how aviation forecasters collaborated with researchers to implement satellite-based NUCAPS CAA data into their CAA MIS forecast process and highlights areas for future research.

\section{Data and methods}

Operational meteorologists typically rely on two categories of data for accurate forecasts: models and observations. Models are either deterministic (e.g., NWP) or probabilistic (e.g., ProbSevere; Cintineo et al. 2014, 2018). Observations can range from in situ measurements (e.g., balloon soundings, surface networks) to remotely retrieved measurements (e.g., radar, satellite imagery, and soundings). Satellite imagery from geostationary platforms typically form the bulk of the observations assessed by aviation forecasters in Alaska. Their high temporal frequency enables visualization of imagery loops that accurately characterize rapidly evolving meteorological features, such as convective storms. Visualization of CAA for aviation forecasting in Alaska, however, is a challenge because traditional forecasting sources are not well suited to observing CAA presence and extent. CAA detection depends on measurements of temperature 
gradients in the vertical and horizontal atmosphere; they are not exact features with distinct boundaries. None of the United States geostationary satellite platforms have hyperspectral infrared (IR) sounders that can measure the vertical atmosphere accurately. Moreover, a CAA event can cover an area encompassing thousands of square kilometers that a few isolated radiosondes cannot fully characterize with in situ measurements at a specific geographic location.

CWSU forecasters need to provide pilots with information on the full 3-D extent of the CAA event including identification of atmospheric temperature locations less than $-65^{\circ} \mathrm{C}$, vertical and horizontal extent, temporal onset, duration, movement, and intensity. It is for these types of observations that satellite soundings from polar-orbiting satellites are particularly well suited. At high latitudes, the temporal frequency of polar-orbiting measurements is enough to track hourly atmospheric change, and the hyperspectral IR sounders, such as CrIS, on these polar-orbiting platforms allow accurate observation of vertical temperature gradients. Given multiple overpasses, each with a 2,200 km-wide swath, the sounders additionally provide accurate spatial observations. The next subsection describes the NOAA operational satellite sounding product, NUCAPS, and how the right type of information is condensed and simplified to enable fast and accurate CAA forecast decision-making.

\section{a. NUCAPS satellite soundings}

NUCAPS generates satellite sounding products from instruments on four polar-orbiting platforms. Two of the platforms, MetOp-A and MetOp-B, are within an hour of each other, with a 09:30 a.m./p.m. local overpass time. The two remaining platforms, JPSS S-NPP and NOAA-20, are within $50 \mathrm{~min}$ of each other with a 01:30 a.m./p.m. local equator overpass time. Each platform is equipped with a microwave (MW) and a hyperspectral IR sounder that measure the atmosphere from pole to pole with a density that increases with latitude. An area near the equator is measured twice a day (ascending and descending nodes), while an area in the Arctic is measured at a higher temporal frequency each day (overlapping ascending and descending nodes) in 2,200 km-wide swaths. Forecasters depend on these polar-orbiting instruments for high density measurements to improve weather forecasts because United States geostationary platforms have large parallax errors at latitudes greater than $60^{\circ} \mathrm{N}$, which includes most of Alaska.
NUCAPS has been a NOAA operational system since 2008 and has been validated extensively against global sets of radiosondes and other observations from validation campaigns (Nalli et al. 2013, 2017; Feltz et al. 2017). NUCAPS soundings include vertical information about temperature $(\sim 1 \mathrm{~K}$ uncertainty in the lower troposphere; Nalli et. al. 2017) and moisture ( $\sim 20 \%$ uncertainty in the lower troposphere; Nalli et. al 2017) as well as trace gases (ozone, carbon monoxide, carbon dioxide, nitrous oxide, nitric acid, and methane), clouds, and surface properties. The NUCAPS soundings of temperature and moisture from the S-NPP suite of instruments were released with the NWS AWIPS-II in 2014 to fill the observational gaps not covered by radiosondes. This was the first time polar-orbiting satellite soundings became routinely available to operational meteorologists. Today, NUCAPS soundings are used to verify forecast model fields, observe complex weather over the ocean and mountains, improve mesoscale situational awareness of the preconvective environment (Zavodsky et al. 2016, 2017; Smith et al. 2018), and monitor synoptic-scale storm evolution (Zavodsky et al. 2013; Berndt et al. 2016; Berndt and Folmer 2018). Additionally, they provide quantitative information about freezing levels, midlevel moisture, and other critical temperature thresholds for severe weather analysis (The Satellite Proving Ground at the Hazardous Weather Testbed 2017; The Satellite Proving Ground at the Hazardous Weather Testbed 2018).

NUCAPS fills a data gap and complements the more traditional data sources forecasters routinely evaluate. The first such source is satellite imagery from the Geostationary Operational Environmental Satellite -R (GOES-R) Series Advanced Baseline Imager (ABI), which typically observes dust, ash, and cloud features at high spatial and temporal resolution. NUCAPS complements these types of imagery by observing the atmospheric change around the features they measure. Measurements of IR and MW are sensitive to changes in temperature (and gaseous absorption) with atmospheric pressure. A full swath of NUCAPS soundings quantifies the vertical and horizontal gradients of mesoscale atmospheric changes within which the features observed by ABI occur. The second traditional source forecasters have used since the 1930s is radiosondes, which measure temperature and moisture at the point of contact with the instruments as the balloon ascends. NUCAPS supplements radiosondes by measuring atmospheric change from the top down 
and averaged over a large region corresponding to the satellite observation field-of-view. A NUCAPS sounding is thus interpreted as a cylindrical observation (with $\sim 50 \mathrm{~km}$ diameter at instrument nadir view and $\sim 150 \mathrm{~km}$ at edge of scan) that measures atmospheric change in vertical layers of $1-3 \mathrm{~km}$ depth, depending on pressure. Not only do NUCAPS soundings observe the areas between radiosonde sites, they also provide atmospheric context for the point-source balloon measurements. Lastly, forecasters routinely use numerical forecast models that depend on probabilistic or convective modeling and parameterization that has strong spatial correlation, smooth gradients, and systematic bias due to simplifications in atmospheric physics. NUCAPS complements models by providing spatially independent soundings and systematic bias primarily limited to the presence of uniform cloud fields. Therefore, NUCAPS is ideal for applications such as CAA that occur under predominately cloudless conditions, and the enhanced polar sampling frequency is another benefit. Another important way in which NUCAPS complements numerical forecast models is that they are independent of each other because models do not assimilate NUCAPS soundings, and NUCAPS does not use models as a first guess.

\section{b. AWIPS-II CAA Gridded NUCAPS operational product}

The Gridded NUCAPS product is the result of a multi-organization collaboration between operational and research scientists, forecasters, and satellite product developers to design a solution for the unique CAA forecast challenge in Alaska (Berndt et al. 2017). This new application and product design succeeded because of the opportunity to collaborate within the framework of the NOAA JPSS PGRR Program Sounding Applications Initiative (Weaver et al. 2018). The NUCAPS soundings can be displayed as Skew-T plots via the National Center Sounding and Hodograph Analysis and Research Program, which allows localized interrogation of individual soundings. However, this is often not enough because CAA has a 3-D structure, and pilots require knowledge of the vertical and horizontal extent of these features so they can avoid them. The fact that NUCAPS soundings are available in 2,200 km-wide swaths makes them suitable to address this data need. This led to the design of a new, experimental product for AWIPS-II, named Gridded NUCAPS, to allow forecasters to visualize and interrogate the full 3-D extent of CAA features. The first prototype of a gridded CrIS sounder product in AWIPS-II was developed by scientists at the University of Wisconsin-Madison Space Science and Engineering Center (SSEC) who gridded the dual-regression sounding product (Smith et al. 2012; Weisz et al. 2013; Weisz et al. 2014) with the Polar2Grid software tool (SSEC 2018) distributed via the Community Satellite Processing Package (CSPP). The Polar2Grid tool transposes swaths of sounding profiles at horizontal pressure layers onto the fixed spatial grids used by AWIPS-II systems. Today there is an official NUCAPS reader for Polar2Grid, but in 2014 the team used an experimental version of Polar2Grid to process NUCAPS products for testing, dissemination, and display in AWIPS-II. Scientists at the NASA Shortterm Prediction Research and Transition (SPoRT) Center developed real-time processing procedures to obtain direct-broadcast (DB) NUCAPS Environmental Data Records (EDRs) (Gambacorta 2013; Gambacorta et al. 2017) from the Geographic Information Network of Alaska (GINA) and processed the data through Polar2Grid. They then used wgrib2 tools to create and format a gridded binary version 2 (GRIB2) file for dissemination, ingest, and display in AWIPS-II (Smith et al. 2015; Zavodsky et al. 2016, 2017). Polar2Grid creates a stack of gridded temperature and moisture layers one pressure level at a time. Of the 100 NUCAPS pressure layers that span the boundary layer to the top of the atmosphere $(0.05 \mathrm{mb}), 58$ tropospheric pressure layers $(>100 \mathrm{mb})$ are made available within AWIPSII to forecasters. The Gridded NUCAPS GRIB2 files contain 58 gridded fields for both temperature and specific humidity, and these are communicated in pressure units $(\mathrm{mb})$ as well as height (meters above ground level) to allow visualization of the data as flight levels. Additionally, the GRIB2 files contain surface pressure, surface temperature, and surface height. The reason NUCAPS soundings are formatted on a uniform model grid is to allow AWIPS-II to process the satellite sounding products in the same way it does model products (e.g., NWP models).

The NOAA operational pathway to all NWS partners for NUCAPS soundings into AWIPS-II typically occurs via the Satellite Broadcast Network (SBN) NOAAPort. The measurements made by instruments onboard S-NPP are downlinked once an orbit is completed (101.44 min) at Svalbard, Norway, which means that NUCAPS soundings reach forecasters over the SBN network between 90 to $240 \mathrm{~min}$ after the time of observation. Derived with data from the Alaska DB 
station at GINA, the Gridded NUCAPS data are made available within AWIPS-II in near-real time within 40 to $60 \mathrm{~min}$ of a satellite overpass and distributed to Alaska Region NWS partners via the Unidata's Local Data Manager (Unidata 2018), thus meeting NWS latency requirements for sounding observations. The CSPP makes NOAA operational algorithms available to worldwide DB stations for real-time data processing, which allows for satellite NUCAPS soundings that mimic radiosonde data to be available within AWIPS-II no later than 60 min after loss of balloon transmission. This latency issue will be resolved for products from NOAA-20 as data will be downlinked twice every orbit ( $\sim 5 \mathrm{~min}$ ) to better support real-time decision-making. For Alaskan forecasters, it is important to accurately determine the onset of a CAA event, both spatially and temporally, as well as its evolution over hours and days. Timely observations result in better CAA MIS products.

Gridded NUCAPS gives forecasters the ability to interrogate NUCAPS observations as a 3-D volume of data much as they interrogate NWP or radar data via plan views and cross sections. An example of the product for a CAA event is shown in Fig. 4 for a plan view and in Fig. 5 for a cross-section view. The Gridded NUCAPS product preserves the spatial resolution and physical integrity of the NUCAPS observations and does not perform horizontal interpolation, hence the blocky appearance. In other words, the Gridded NUCAPS product does not interpolate the sounding observations but instead bins them to a regularized grid so the retrieved observations are preserved. Gaps can exist in the Gridded NUCAPS fields as seen in Fig. 4 and Fig. 5, and this is most commonly due to uniform cloud cover or poor retrieval quality. Clouds obscure IR radiative transfer through the atmosphere and prevent the retrieval of moisture and temperature profiles. An important difference between NUCAPS soundings and radiosondes is that the latter measures the thermodynamic state through clouds, whereas NUCAPS measures the thermodynamic state past or around clouds. NUCAPS employs a method known as "cloud clearing" (Susskind et al. 2003) to enable a sounding profile retrieval in partly cloudy conditions. Cloud clearing derives a cloud-free radiance measurement from a cluster of satellite instrument footprints (nine instruments for CrIS on S-NPP, and four instruments for the Infrared Atmospheric Sounding Interferometer on MetOp-A and MetOp-B), each measuring a different section of the cloud field. Cloud clearing does not work when the cluster of footprints observes the same solid

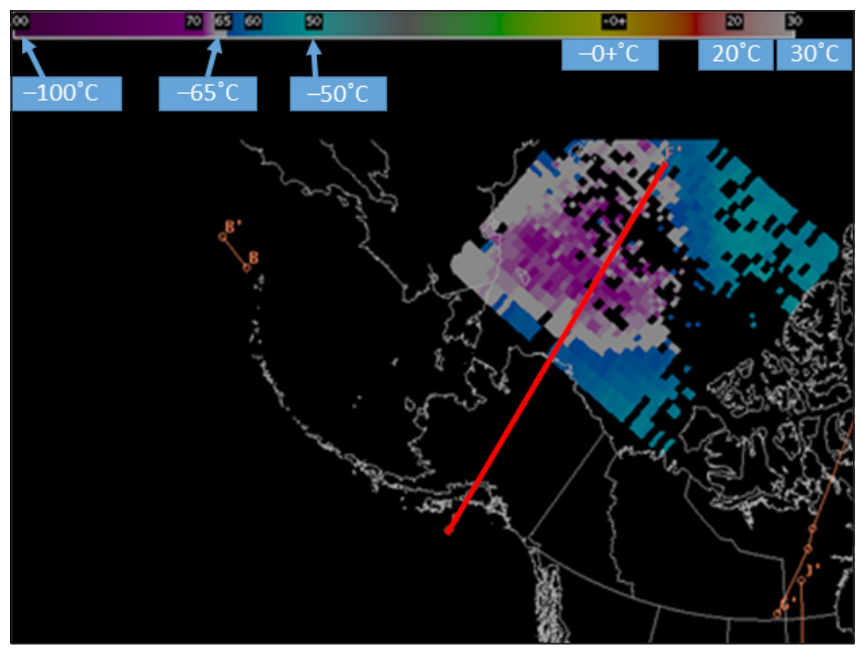

Figure 4. AWIPS-II plan view of the CAA NUCAPS temperature product at $212 \mathrm{hPa}$ on 1700 UTC 8 December 2016. The CAA feature is identified where temperature observations are less than $-65^{\circ} \mathrm{C}$, indicated here in gray and purple colors.

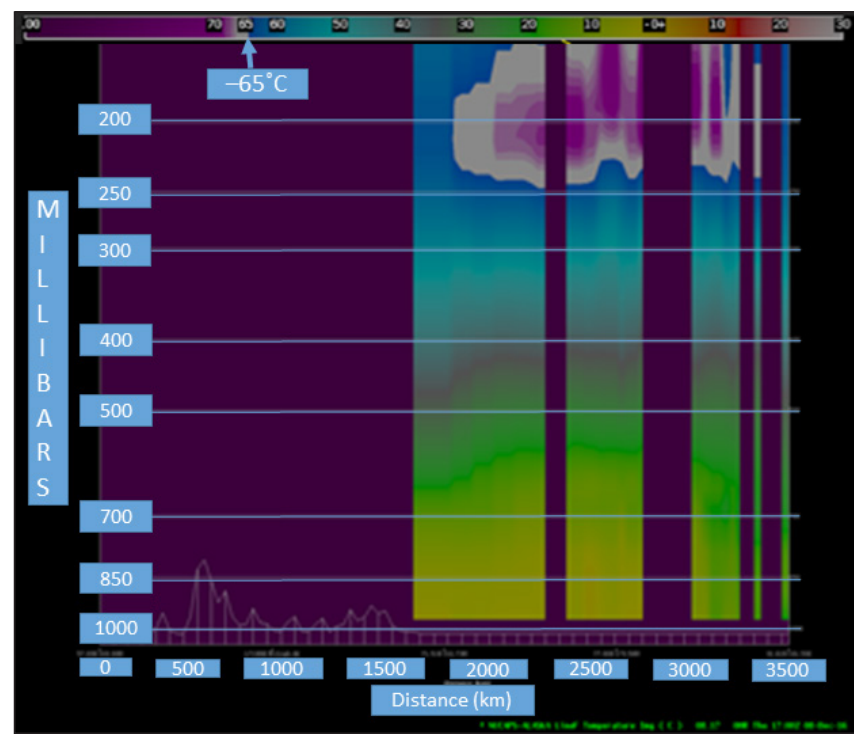

Figure 5. AWIPS-II cross section of the CAA NUCAPS product, 1700 UTC 8 December 2016. The cross section was derived from the red line overlaid on the image in Fig. 4. The color scale at the top of the image displays temperatures in degrees $\mathrm{C}$ and is the same temperature scale as in Fig. 4.

cloud deck and there is no variation in cloud cover. The retrieval quality of satellite soundings in regions with complex cloud structures, fractions, and edges is a known challenge in the sounding community and can limit some forecasting applications (Susskind et. al. 2003; Berndt et. al. 2018). 
The Gridded NUCAPS product in AWIPS-II allows forecasters to quickly identify CAA areas of $-65^{\circ} \mathrm{C}$ or less (gray and purple colors in Fig. 4 and Fig. 5) as well as assess the magnitude and location (both horizontally and vertically) of the coldest core of air. The products in Fig. 4 and Fig. 5 use a form of data compression whereby the color scheme is used to highlight features for quick identification of hazards (Smith et al. 2018). If forecasters, operating under time pressure, had to search through all the NUCAPS soundings one by one, the satellite data product would be much less useful on the forecast desk. In the discussion below and to date, the CWSU forecasters use both the NUCAPS soundings and Gridded NUCAPS products to assess areas of CAA. Both AWIPS-II visualization products provide value for different modes in forecasting. Forecasters can use NUCAPS soundings to complement existing radiosondes with greater spatial coverage (more SkewTs to view) to enhance situational awareness or fill in the observational gaps when radiosondes are not available (Fig. 6). Although the NUCAPS soundings (Fig. 6a) are smoother than radiosonde soundings (Fig. $6 \mathrm{~b}$ ), forecasters can assess the magnitude and height of CAA vertically with sufficient accuracy. Moreover, the swaths of NUCAPS soundings are independent of each other, and forecasters can loop through a sequence of overlapping swaths one by one in order to compile a more complete picture of the CAA area in terms of size, change of intensity over time, and movement.

\section{c. CIRA CAA operational product}

The first web-based NUCAPS display of CAA features was developed by researchers at CIRA in conjunction with the Anchorage CWSU forecasters. This display complements AWIPS-II because it is available to the public, specifies the top and bottom of the CAA layer in flight levels so it can easily be incorporated into the CWSU's MIS, and offers Northern Hemisphere views in addition to regional Alaskan views. The broader views outside of Alaska airspace provide the opportunity for international collaboration regarding CAA events that often span geopolitical borders.

The CIRA web-based display (Fig. 7) differs from the Gridded NUCAPS display in AWIPS-II in several important ways. First, it blends data from the last 14 hours of satellite orbits to form a more spatially continuous display. Second, it indicates the minimum value of the NUCAPS temperature profile irrespective of the height at which it occurred, which can be anywhere
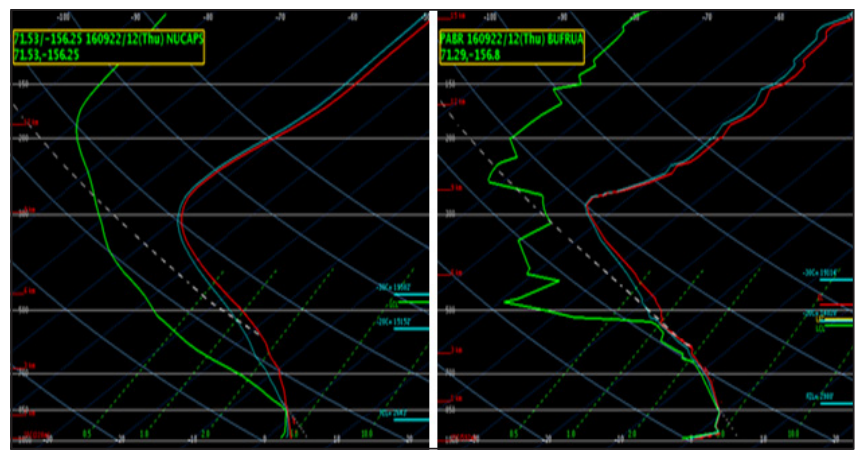

Figure 6. AWIPS Skew-T displays from 1200 UTC 22 September 2016 near Barrow, AK, of (a) NUCAPS sounding, and (b) radiosonde sounding. Both soundings indicate temperature, dew point, and the tropopause height, with the only difference being the smoothed lines in the NUCAPS sounding, which is applied in the NUCAPS algorithm.

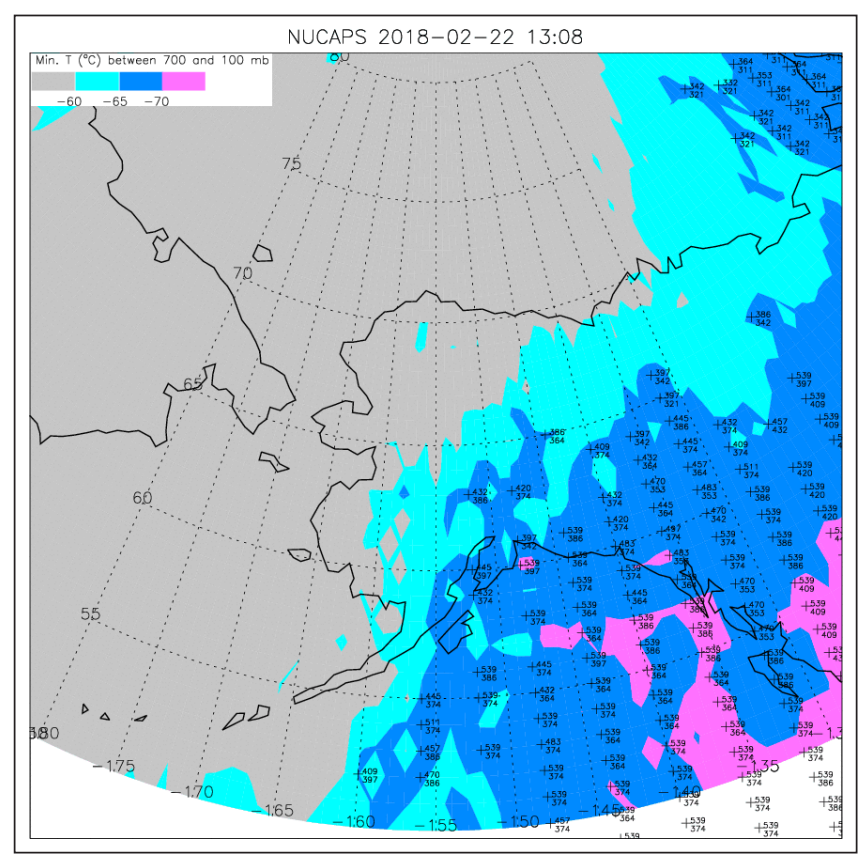

Figure 7. AK regional view from the CIRA web page at 1308 UTC 22 February 2018. The color shades depict the CAA feature between approximately $700 \mathrm{mb}$ and approximately $100 \mathrm{mb}$. A '+' is displayed where the minimum temperature occurs below FL450, with the upper and lower bounds of the air temperature at or below $-65^{\circ} \mathrm{C}$ given in hundreds of $\mathrm{ft}$.

between approximately $700 \mathrm{mb}$ and approximately $100 \mathrm{mb}$. Third, it spatially interpolates the temperature values into four color-coded categories: above $-60^{\circ} \mathrm{C}$, between $-60^{\circ} \mathrm{C}$ and $-65^{\circ} \mathrm{C}$, between $-65^{\circ} \mathrm{C}$ and $-70^{\circ} \mathrm{C}$, and below $-70^{\circ} \mathrm{C}$. Finally, using ' + ' symbols, it indicates 
where the CAA feature (temperatures below $-65^{\circ} \mathrm{C}$ ) extends below flight level 450 (FL450). Pilots typically use flight level as a measure of the plane's height above mean sea level. It is a pressure altitude with units given in hundreds of $\mathrm{ft}$, preceded by 'FL'. For example, FL450 is approximately $45000 \mathrm{ft}$ above mean sea level.

In addition to displaying CAA information from S-NPP NUCAPS retrievals, data from the Microwave Integrated Retrieval System (MiRS) (Boukabara et al. 2011) also are shown. The MiRS is a microwave-only retrieval algorithm which, like NUCAPS, can run on all MW instruments on polar-orbiting platforms. Currently the website uses MiRS from the ATMS instrument aboard S-NPP as well as the Advanced Microwave Sounding Unit flying aboard NOAA-18, NOAA-19, Metop-A, and Metop-B (Kidder et al. 2000). In addition, the web page contains equivalent displays using data from the Global Forecast System model. The web page serves, not only as a backup for the Anchorage CWSU in case of an AWIPS-II outage, but also provides CAA information for users without access to AWIPS-II.

\section{Analysis and discussion}

NUCAPS sounding products were evaluated over the course of two years to determine the quality of this new product and whether it accurately detects the onset, spatial extent, and evolution of CAA events. These evaluations took place in the winter months of 2016-2017 and 2017-2018 at the Anchorage CWSU because CAA regularly occurs there, thus forecasters can assess the value of NUCAPS sounding products in generating CAA MISs. The first CAA assessment tested the viability of a NUCAPS CAA product to support CWSU issuance, or non-issuance, of the MIS text product. The second CAA assessment was a followon to the 2016-2017 assessment and addressed all the issues forecasters identified as needing improvements, such as the ability to display the data in AWIPS-II as flight levels. Forecasters used the CAA products on the CIRA web display and within AWIPS-II throughout both assessments. During the first assessment (20162017), a CAA MIS was in effect 57 out of 121 days, and during the second assessment (2017-2018), a CAA MIS was in effect 47 out of 85 days. The month with the most occurrences was February 2018, when a CAA MIS was in effect 23 out of 28 days.

\section{a. 2016-2017 CAA winter assessment case}

On 10 January 2017 a large area of CAA formed over Alaska airspace above FL350 from the Beaufort Sea, across central Alaska, and down to the southern edge of the Panhandle. The Anchorage CWSU issued a CAA MIS to warn air traffic controllers and pilots about the cold air mass. The CAA feature was initially detected using NWP data, which indicated a large cold pocket with temperatures less than $-65^{\circ} \mathrm{C}$ above FL350. Forecasters loaded Gridded NUCAPS data in AWIPSII to find out how close the temperature data matched the NWP data in order to validate the area coverage and heights of the CAA. They also looked at Aircraft Meteorological Data Relay (AMDAR) reports to obtain precise temperature data from aircraft flying through or near the CAA area. In this case, the AWIPS-II NUCAPS cross section displayed $-65^{\circ} \mathrm{C}$ or less above FL340, which was verified by an AMDAR report of $-65^{\circ} \mathrm{C}$ at $36900 \mathrm{ft}$ over the northern Gulf of Alaska (Table 1). Forecasters also used available sounding data within the CAA area to compare NWP, Gridded NUCAPS, and the CIRA web page data with actual temperatures. The Barrow sounding (Fig. 8) depicted a cold layer of $-65^{\circ} \mathrm{C}$ or less from approximately FL332-FL370 and also above FL480, which closely matched the NUCAPS CAA level of FL340 and above. Finally, forecasters used the CIRA web display to refine the CAA details in

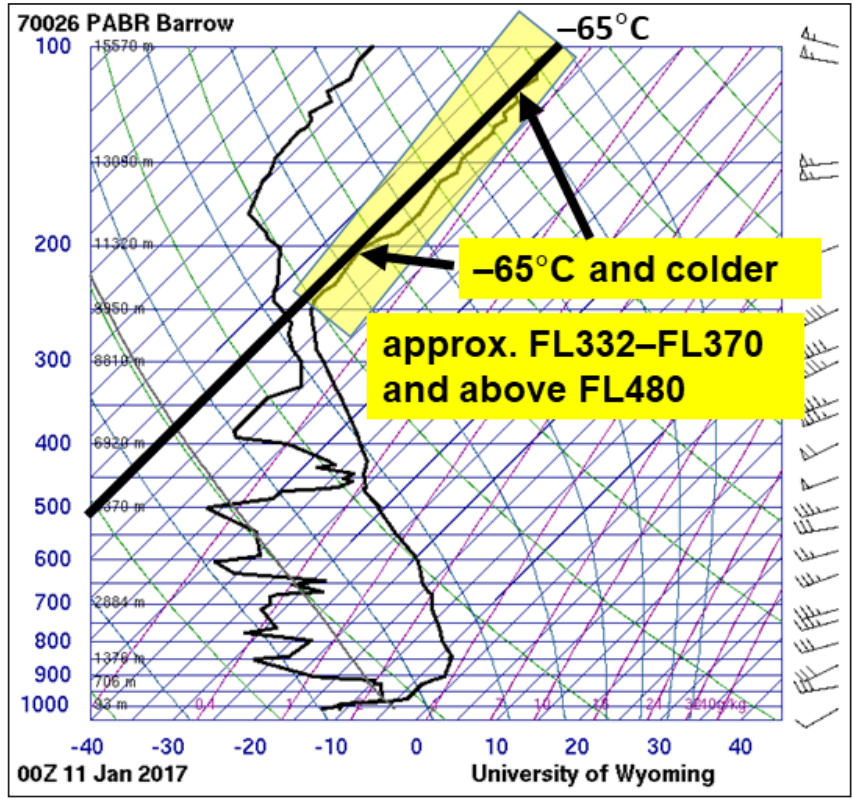

Figure 8. Barrow, AK, sounding at 0000 UTC 11 January 2017. Temperatures and flight levels near or colder than $-65^{\circ} \mathrm{C}$ are highlighted in yellow 
Table 1. AMDAR data from 0143 UTC 11 January 2017 for an aircraft taking off from Anchorage and heading towards the southeast over the Gulf of Alaska and Alaska Panhandle. Temperatures less than $-65^{\circ} \mathrm{C}$ are depicted from $36900 \mathrm{ft}$ to $38990 \mathrm{ft}$.

\begin{tabular}{|c|c|c|c|}
\hline P_alt (ft) & $\mathbf{m b}$ & $\mathbf{t}\left({ }^{\circ} \mathbf{C}\right)$ & w_dir/w_spd (kt) \\
\hline 33990 & 250 & -57.9 & ---- \\
\hline 36900 & 218 & -65.0 & $2 \% 09$ \\
\hline 36940 & 217 & -65.5 & $34^{\circ} / 050$ \\
\hline 36950 & 217 & -65.1 & $38^{\circ} / 038$ \\
\hline 36970 & 217 & -65.0 & $39^{\circ} / 035$ \\
\hline 36980 & 217 & -65.3 & $38^{\circ} / 047$ \\
\hline 36990 & 217 & -64.8 & $219^{\circ} / 027$ \\
\hline 37000 & 217 & -65.1 & $31^{\circ} / 048$ \\
\hline 37020 & 216 & -66.0 & $30^{\circ} / 053$ \\
\hline 37030 & 216 & -65.3 & $33^{\circ} / 047$ \\
\hline 37100 & 216 & -66.5 & $28^{\circ} / 052$ \\
\hline 38900 & 198 & -66.6 & $26^{\circ} / 052$ \\
\hline 38940 & 197 & -69.0 & $31^{\circ} / 049$ \\
\hline 38970 & 197 & -62.6 & $25^{\circ} / 030$ \\
\hline 38980 & 197 & -67.0 & $24^{\circ} / 050$ \\
\hline 38990 & 197 & -66.0 & $29^{\circ} / 050$ \\
\hline 39000 & 197 & -64.8 & $22^{\circ} / 043$ \\
\hline
\end{tabular}

terms of areal coverage, heights, and movement.

During this CAA event, the Gridded NUCAPS data (Fig. 9 and Fig. 10) closely matched NWP data, station sounding data, and AMDAR data, which increased the forecaster confidence in using Gridded NUCAPS data to complement NWP data in determining the vertical and horizontal extent of CAA. Even with large blocks of missing NUCAPS data due to cloud cover that day, forecasters had enough information to trace an outline of the CAA area located in Alaska airspace. The amount of cloud cover does have an impact on the Gridded NUCAPS data but varies on a case-to-case basis depending on where the CAA area is located with respect to the cloud cover. In this case, NUCAPS data helped to fill in the gaps where no in situ observations or radiosondes were available, which enabled CWSU forecasters to provide controllers and pilots with a tool (in the form of an MIS) to use to avoid the area of CAA or to implement protective measures to reduce the fuel freezing effects of cold air. b. 2016-2017 CAA winter assessment feedback summary

NASA SPoRT developed an online feedback website for Anchorage CWSU forecasters to provide specific details regarding the performance of Gridded NUCAPS data. Likert scale (Likert 1932) questions were used to rate the impact of the product on the forecasting and decision process to issue an MIS. There were 18 online feedback responses from 1 December 2016 to 30 March 2017. Gridded NUCAPS was rated by forecasters with a "very large" impact on the forecast process for 6 events, "some" impact for 2 events, "small" impact for 3 events, and "very small" impact for 7 events. Because of the constraints of the CWSU's fast-paced operational environment, the Gridded NUCAPS products were not fully implemented in AWIPS-II or the CIRA web display before the assessment period began. Before the Gridded NUCAPS products were fully operational, most forecaster feedback responses indicated that NUCAPS had a "very small" or "small" impact on the forecast decision process. Forecasters also rated their confidence in the Gridded NUCAPS as "low" at the beginning of the CAA assessment when the forecasters 


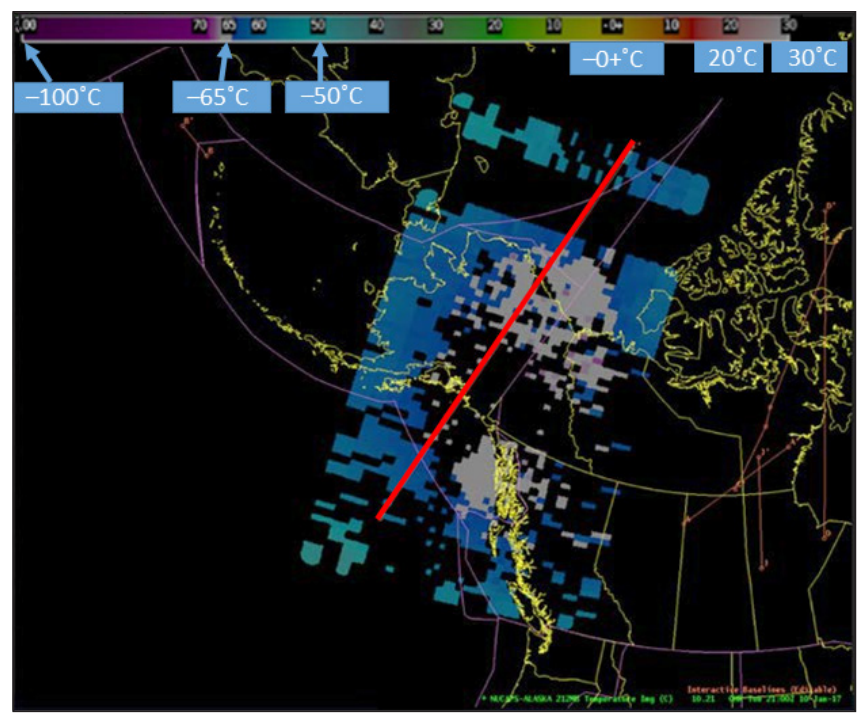

Figure 9. AWIPS-II plan view of the 212 hPA CAA NUCAPS temperature product on 10 January 2017. The CAA feature is identified where temperature observations are less than $-65^{\circ} \mathrm{C}$, indicated here in gray and light purple colors.

were still becoming familiar with the new Gridded NUCAPS products and before a warm temperature bias was fixed in CIRA's web-based product. Once the warm bias was realized by CWSU forecasters and reported through the online feedback form, developers quickly fixed the warm temperature interpolation issue. The most common reasons for Gridded NUCAPS having a "small" or "very small" impact on the decision to issue an MIS were because the forecaster had confidence in another analysis/model or real-time observation, the satellite orbit did not display Gridded NUCAPS data over the CAA area or missed it entirely, Gridded NUCAPS did not match the magnitude of the feature compared to other observations, or Gridded NUCAPS data were not available on AWIPS-II.

NASA SPoRT researchers and forecasters were able to quickly fix any Gridded NUCAPS researchto-operations (R2O) issues because of the timely feedback. As developers worked out initial bugs in Gridded NUCAPS products and forecasters became more familiar with the products over the assessment period, they developed more confidence and rated it as having a higher impact and more usefulness in their forecast process. Forecasters indicated Gridded NUCAPS had a "very large" impact on issuance of a forecast product when it was similar to the NWP product, thus increasing the forecaster's confidence in the NWP product. Forecasters also stipulated that they

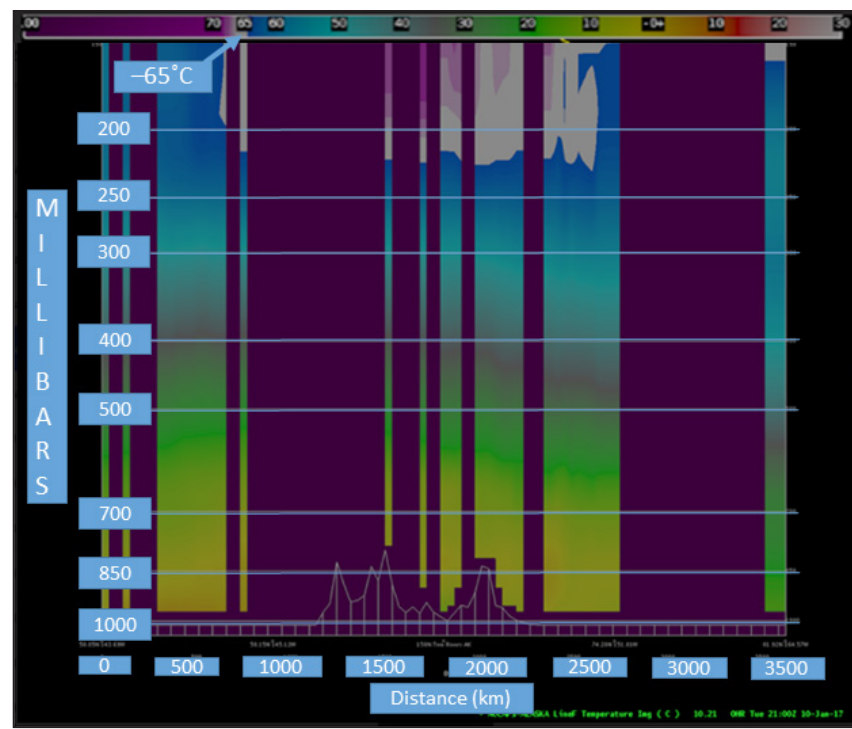

Figure 10. Gridded NUCAPS data cross section displaying temperatures less than $-65^{\circ} \mathrm{C}$ in gray and light purple colors at the top of the image, with the base of the CAA located at approximately FL340 on 10 January 2017. The cross section was derived from the red line overlaid on the image in Fig. 9. The color scale at the top of the image displays temperatures in degrees $\mathrm{C}$ and is the same as in Fig. 9.

chose NUCAPS data over NWP data when both sets of data were different, which reflected the trust forecasters gained in using NUCAPS data when the NWP data did not capture the CAA event very well. By the end of the assessment period, 8 of the 18 responses indicated forecasters had "high" confidence in the Gridded NUCAPS product, indicating the forecasters were becoming more familiar with the product and also were gaining confidence to integrate it into their operational analysis and forecast decision process. As a result of the initial assessment, forecasters conducted post-event analyses of some of the CAA events that occurred during the period (Weaver et al. 2018) and were eager to continue using Gridded NUCAPS and soundings to fill in the observational gaps.

\section{c. 2017-2018 CAA winter assessment case}

On 14 February 2018 the pilot of a Federal Express (FedEx) McDonnell Douglas-11 (MD-11) flying from Memphis to Anchorage asked the Anchorage ARTCC air traffic controller for permission to descend from FL360 to an altitude below FL340 because of a cold fuel temperature indicator on the instrument panel. On that particular day there was a large region of CAA with 


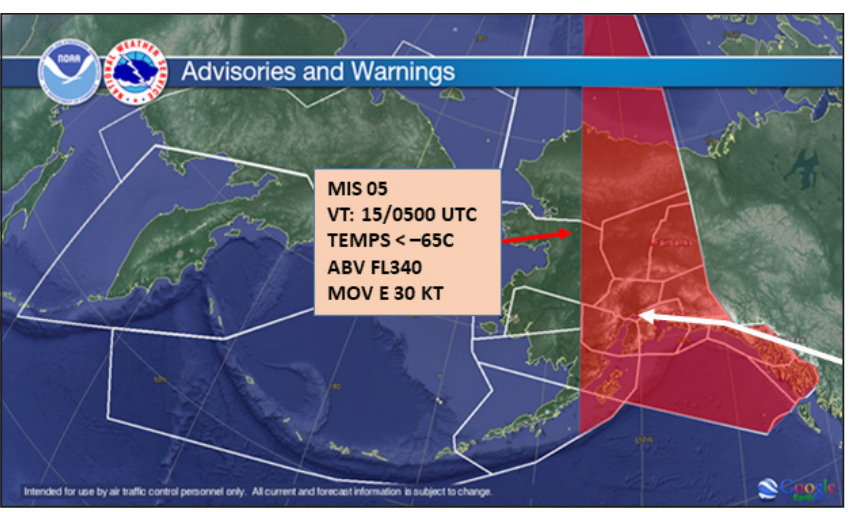

Figure 11. CAA MIS 05. The CAA area is highlighted in red. The FedEx MD-11 flight path is depicted by the white line with the arrow pointing to the final destination of Anchorage, AK. The CAA MIS displayed in graphic form assists the air traffic controllers in visualizing the total amount of AK airspace affected by CAA.

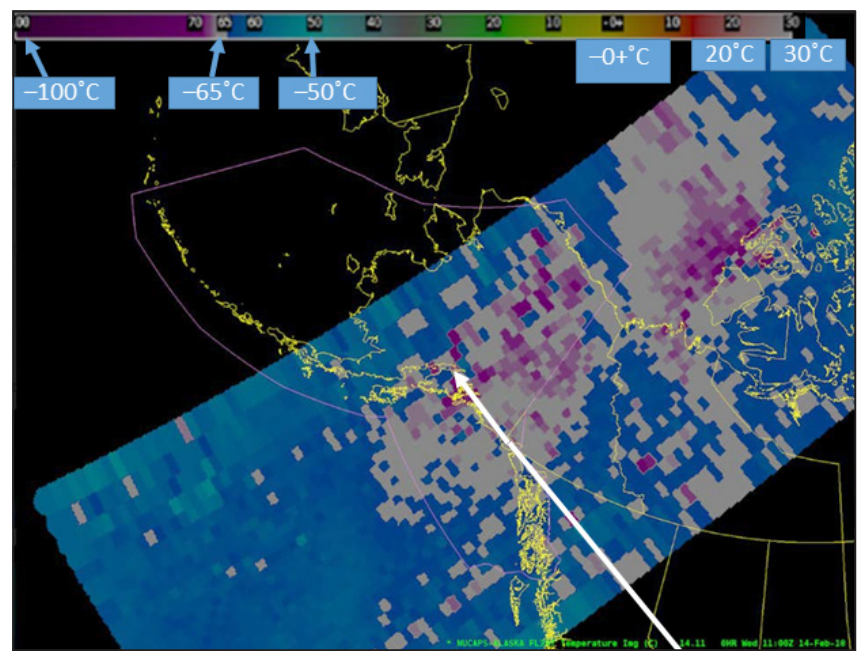

Figure 12. The Gridded NUCAPS product in AWIPSII displaying temperatures at FL397 at 1100 UTC 14 February 2018. The CAA feature is identified where temperature observations are less than $-65^{\circ} \mathrm{C}$, indicated here in gray and purple colors. The color scale at the top of the image displays temperatures in degrees $\mathrm{C}$ and is the same as in Fig. 9. The FedEx MD-11 flight path is depicted by the white line with the arrow pointing to the final destination of Anchorage, AK.

temperatures less than $-65^{\circ} \mathrm{C}$ extending from the northcentral United States all the way through Canada and into eastern Alaska, directly along the flight path of the FedEx MD-11. As the FedEx MD-11 travelled through Edmonton airspace, the Canadian air traffic controllers directed the pilot to ascend to FL360, directly into the CAA area. When the FedEx MD-11 crossed over

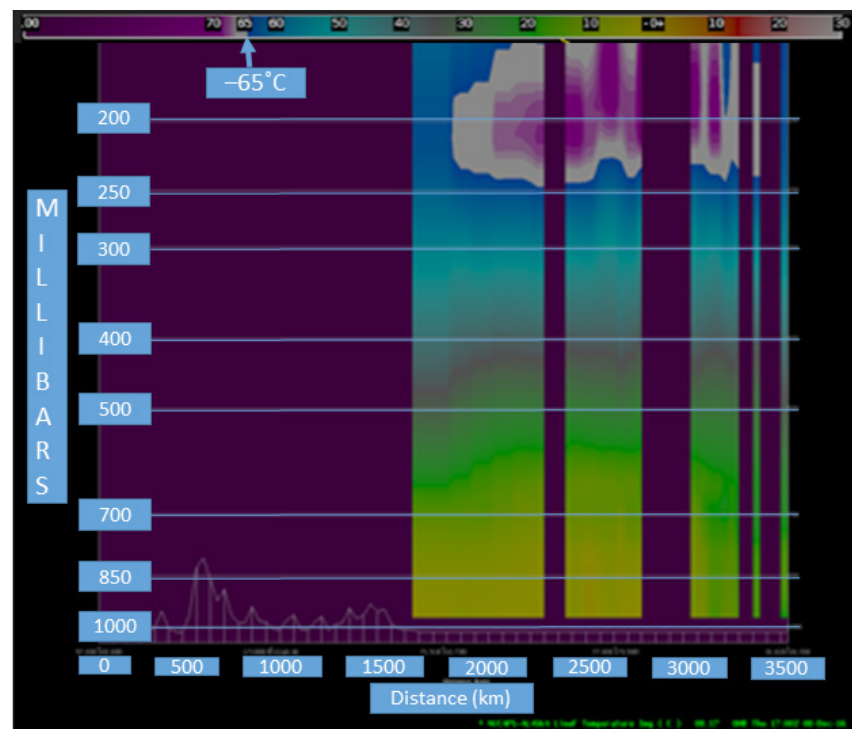

Figure 13. Gridded NUCAPS data cross section displaying temperatures less than $-65^{\circ} \mathrm{C}$ in gray and purple colors at the top of the image, with the base of the CAA located at approximately FL330 on 14 February 2018. The color scale at the top of the image displays temperatures in degrees $\mathrm{C}$ and is the same as in Fig. 12.

into Alaska airspace over the Panhandle in southeast Alaska, the pilot immediately requested permission to descend to warmer air below FL340. CAA MIS 05 was in effect at the time for temperatures less than $-65^{\circ} \mathrm{C}$ above FL340 across a large portion of northern, central, and eastern Alaska airspace (Fig. 11). Figure 11 depicts the operational CAA product in graphic form that the CWSU provided to the Anchorage ARTCC controllers on 14 February 2018 so they could visualize the airspace affected by CAA.

After comparing NWP data and Gridded NUCAPS data to actual sounding temperatures, forecasters determined that NWP data did not reflect actual conditions across the Alaska airspace. CWSU forecasters used Gridded NUCAPS data in lieu of NWP data on 14 February 2018 because the NUCAPS data (Fig. 12 and Fig. 13) were in excellent agreement with soundings (Fig. 14) over much of the state, and the close similarities increased their confidence in issuing an MIS for the CAA event. The Gridded NUCAPS data helped forecasters pinpoint the CAA area, flight levels, and intensity change and provided Anchorage ARTCC air traffic controllers with the necessary information to immediately approve the pilot's request to descend safely to a lower altitude. 


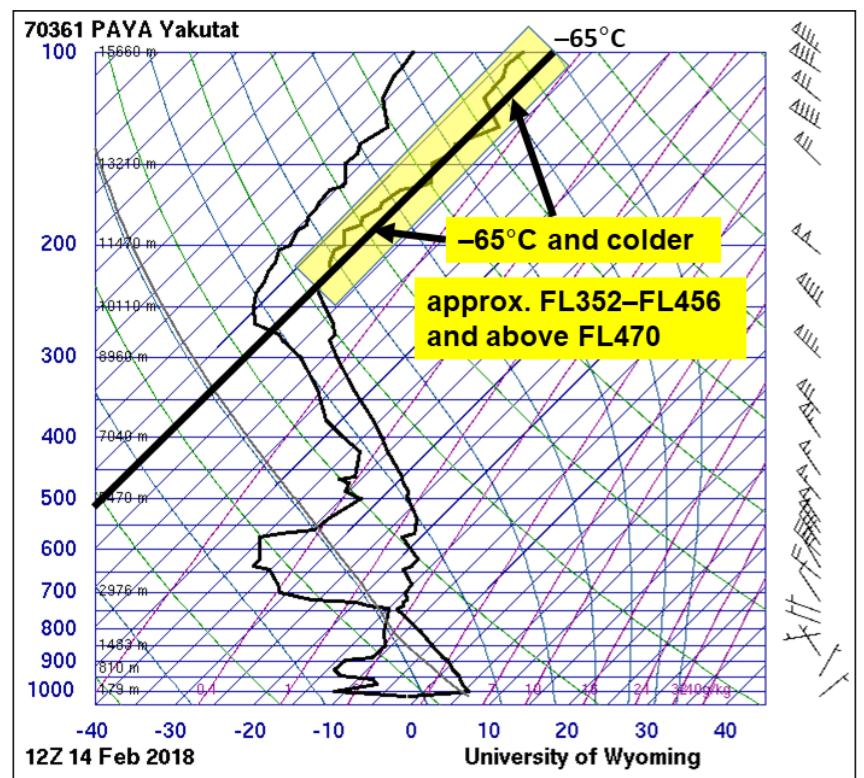

Figure 14. Yakutat, AK, sounding at 1200 UTC 14 February 2018. Temperatures and flight levels near or colder than $-65^{\circ} \mathrm{C}$ are highlighted in yellow.

\section{d. 2017-2018 CAA winter assessment feedback summary}

During the second assessment period forecasters had greater familiarity and confidence in the Gridded NUCAPS, and their feedback indicated the value and impact of Gridded NUCAPS as a critical part of their decision-making process. Seventy-seven percent of the feedback indicated Gridded NUCAPS had a "large" to "very large" impact on the forecast process, specifically referring to the forecaster's decision to issue or not issue a CAA MIS product based on Gridded NUCAPS data. Gridded NUCAPS was rated with a "very large" impact on the forecast process for 8 events, "large" impact for 2 events, and "very small" impact for 3 events. On 20 February 2018 the Gridded NUCAPS had a "very small" impact on the forecast process because the data were latent and unavailable. The Gridded NUCAPS was rated with a "very small" impact on 22 March 2018 and on 30 March 2018 because the forecaster had confidence in another analysis/model or real-time observation, and the Gridded NUCAPS missed the location, due to the satellite orbit, or magnitude of the feature compared to other observations. Eighty-two percent of the time NUCAPS was similar to NWP and increased forecasters' confidence in NWP, and sixtyseven percent of the time NUCAPS was similar to upper air temperature observations and increased forecasters' confidence in the event. The feedback results affirmed the forecasters were able to assimilate the Gridded NUCAPS into their forecast decision process.

The occurrence of several large-scale CAA outbreaks during the assessment period raised awareness among the Anchorage CWSU forecasters and ARTCC personnel concerning the impacts very cold temperatures have on aviation operations. With NUCAPS available to fill the observational gaps, the forecasters had greater confidence in communicating CAA impacts to their customers, which increased the CAA hazards dialogue between the CWSU and the FAA. CWSU forecasters emphasized the importance of obtaining temperature data from pilots at various flight levels and solicited pilot reports directly from air traffic controllers when aircraft were flying through or close to CAA areas. For the first time, CWSU forecasters heard directly from air traffic controllers when pilots requested permission to change their flight level to avoid CAA. This real-time feedback helped verify CAA areas and flight levels and validated Gridded NUCAPS data.

Long-lived CAA events with flight level temperatures as cold as $-74^{\circ} \mathrm{C}$ across Canada and Alaska during the 2017-2018 assessment also raised attention to the impacts of low fuel temperatures. During such an event in February 2018 when an aircraft descended from FL400 to FL340 due to temperatures of $-70^{\circ} \mathrm{C}$, airline dispatchers were directed to the Anchorage CWSU website (www.aviationweather. gov/cwamis/data?loc=paza) where MISs are displayed to obtain the latest CAA information. Events such as these help raise CAA MIS product awareness among pilots, air traffic controllers, and airline dispatchers, and increased awareness may lead some airlines to plan their flight levels accordingly in order to fly the most efficient and safest route possible. Pilots, air traffic controllers, and forecasters also must keep in mind that fuel can freeze even when aircraft have flown out of the CAA area because it takes a while for fuel to warm up again (Malmquist 2014). In one instance, an aircraft flying from Canada over the Gulf of Alaska reported fuel temperatures of $-65^{\circ} \mathrm{C}$ after they flew out of a CAA MIS area located over the Alaska Panhandle.

\section{Conclusions}

The challenge of CAA forecasting is unique to the Anchorage CWSU because of the prominence of $\mathrm{CAA}$ at high latitudes. When temperatures are $-65^{\circ} \mathrm{C}$ or less, jet fuel "waxing" or water crystallization in the 
fuel may occur, which can result in a loss of engine performance due to restricted fuel flow. After the British Airways crash in 2008, CAA forecasts became an important aspect of the Anchorage CWSU forecast process (Werner 2018). With only one forecaster assigned to each shift at the CWSU, there is little time to assess the data-sparse environment for CAA given additional aviation hazard forecasting responsibilities. To address this forecast challenge, the JPSS PGRR Program Sounding Applications Initiative developed the capability to provide Gridded NUCAPS planview and cross-section displays of NUCAPS sounding observations in AWIPS-II.

In order to develop a Gridded NUCAPS CAA product, software developers at the University of Wisconsin SSEC developed a NUCAPS reader for the SSEC-developed Polar2Grid software, and the team used an experimental version of Polar2Grid to process the NUCAPS data for dissemination and display in AWIPSII. NASA SPoRT scientists set up real-time processing to obtain CSPP NUCAPS EDRs from GINA's DB station, process the data through Polar2Grid, and then format the data for dissemination, ingest, and display in AWIPS-II. The entire process, from the initial gathering of satellite data to displaying the Gridded NUCAPS products in AWIPS-II, takes place within 40 to $60 \mathrm{~min}$ of the satellite overpass. Forecasters can use Gridded NUCAPS products to enhance situational awareness or fill in the observational gaps when radiosondes are not available and also to explicitly assess the magnitude and the horizontal and vertical extent of the CAA.

A NUCAPS plan-view CAA product was first developed by researchers at CIRA and functioned as the basis for the initial AWIPS-II visualization. With the CIRA web display as a first step, application of innovative techniques to develop a CAA product in AWIPS-II allowed the forecasters to fully integrate analysis of NUCAPS soundings into their forecast process. The CWSU forecasters use both the NUCAPS soundings and Gridded NUCAPS products to assess areas of CAA. Both AWIPS-II visualizations provide value for different modes in forecasting, real-time decision-making, and situational awareness. The CIRAbased web display provides value-added information and serves as a backup for forecasters when AWIPSII is unavailable. Additionally, it can be easily linked to public forecasts and can be used as a tool for international collaboration regarding CAA events. The unique aspect of the CIRA CAA product is that it shows the horizontal extent of the CAA and specifies the top and bottom of the CAA layer in flight levels, which can be incorporated easily into the CWSU's MIS.

Forecasters at the Anchorage CWSU evaluated the Gridded NUCAPS in their operational environment during the 2016-2017 and 2017-2018 winter seasons. The initial assessment tested the feasibility of a NUCAPS CAA product to support CWSU issuance of the MIS text product, and the second assessment was used to fine-tune NUCAPS products for operational use. CWSU forecasters were able to provide immediate O2R feedback during both assessments. This was invaluable in assessing the quality of Gridded NUCAPS data on a near real-time basis and resulted in timely $\mathrm{R} 2 \mathrm{O}$ improvements that led to increased forecaster confidence in using Gridded NUCAPS data to produce CAA MISs.

Despite the overall positive impacts of using Gridded NUCAPS data to produce and verify CAA MISs, there were a few instances during both assessments when Gridded NUCAPS data were not available on AWIPSII, or the Gridded NUCAPS data were available but did not line up with the CAA area because of the S-NPP orbit. There were also times when the Gridded NUCAPS data did not closely match the radiosonde and NWP data. Cloud cover also can have an impact on the accuracy of Gridded NUCAPS data (Berndt et al. 2018, Nalli et al. 2017), and poor-quality data in cloudy regions were filtered out of the product, leaving gaps. Forecasters also highlighted Gridded NUCAPS latency issues during both assessments, which were especially evident during the initiation of CAA events. The JPSS Sounding Applications Initiative is addressing forecaster operational requirements such as latency and preservation of high-quality data.

The CAA winter assessments highlighted the successful transfer of research data into an operational product used in daily aviation operations. There was a clearly stated need from operational forecasters for satellite-based data to bridge the gaps over a datasparse region, and researchers created and delivered satellite-based products in a format that was compatible in AWIPS-II for easier integration into the forecast workflow. Because of the success of this multiorganizational partnership, Gridded NUCAPS will be officially released in 2019 within the operational AWIPS-II, and forecasters throughout the NWS will have access to Gridded NUCAPS data to explore new applications. Future areas for Gridded NUCAPS research applications in aviation hazard forecasting include detecting areas of clear-air turbulence, 
mountain-wave turbulence, and icing over data-sparse areas.

Acknowledgments: The authors would like to thank Dr. Mitch Goldberg, who provided funding to tackle the CAA project through the JPSS PGRR Program. Thanks also to Kristine Nelson, former NWS Anchorage CWSU Meteorologist-in-Charge (MIC), who initiated the CAA project, and Carrie Haisley, the current NWS Anchorage CWSU MIC, who facilitated the project. The authors appreciate the operational feedback given by Christopher Waterhouse, Anchorage CWSU forecaster, and the efforts by Eric Stevens, (University of Alaska Fairbanks, GINA) to provide near real-time Gridded NUCAPS data in AWIPS-II. Finally, we could not have transitioned an idea into an operational aviation product without the hard work of Dr. Chris Barnet, the NUCAPS architect; Elisabeth Weisz, SSEC/CIMSS/ UW-Madison, who prototyped the gridded sounding product (from the CSPP DR algorithm) in AWIPSII; David Hoese, SSEC/CIMSS/UW-Madison, the developer of the CSPP Polar2Grid; and Lori Schultz, NASA/SPoRT, who developed training material and quick guides for NWS forecasters.

\section{REFERENCES}

Bachtel, B., and Co-authors, 2001: Polar route operations. $A E R O, 16,11-21$. [Available online at www.boeing. com/commercial/aeromagazine/aero_16/polar_route ops.pdf.]

Berndt, E., and M. Folmer, 2018: Utility of CrIS/ATMS profiles to diagnose extratropical transition. Results Phys., 8, 184-185, Crossref.

, B. T. Zavodsky, and M. J. Folmer, 2016: Development and application of atmospheric infrared sounder ozone retrieval products for operational meteorology. IEEE Trans. Geosci. Remote Sens., 54, 958-967, Crossref. , N. Smith, K. White, and B. Zavodsky, 2017: Development and application of gridded NUCAPS for operational forecasting challenges. JPSS Science Seminar. [Available online at www.jpss.noaa.gov/ assets/pdfs/science_seminars/presentations/JPSS Seminar_NUCAPS_Berndt.pdf.]
, and Co-authors, 2018: An overview of NUCAPS soundings research to operations activities to support operational forecasting challenges. Recorded presentation. 2018 Alaska Center for Climate Assessment and Policy Virtual Alaska Weather Symposia. Fairbanks, AK. [Available online at https://accap.uaf.edu/webinar/ overview-nucaps-soundings-research-operationsactivities-support-operational-forecasting]

Boukabara, S.-A., and Co-authors, 2011: MiRS: An allweather 1DVAR satellite data assimilation and retrieval system. IEEE Trans. Geosci. Remote Sens., 49, 32493272, Crossref.

Cintineo, J. L., M. J. Pavolonis, J. M. Sieglaff, and D. T. Lindsey, 2014: An empirical model for assessing the severe weather potential of developing convection. Wea. Forecasting, 29, 639-653, Crossref. , and Co-authors, 2018: The NOAA/CIMSS ProbSevere model: Incorporation of total lightning and validation. Wea. Forecasting, 33, 331-345, Crossref.

Feltz, M. L., L. Borg, R. O. Knuteson, D. Tobin, H. Revercomb, and A. Gambacorta, 2017: Assessment of NOAA NUCAPS upper air temperature profiles using COSMIC GPS radio occultation and ARM radiosondes. J. Geophys. Res.: Atmos., 122, 9130-9153, Crossref.

Gambacorta, A., 2013: The NOAA Unique CrIS/ATMS Processing System (NUCAPS): Algorithm theoretical basis documentation, version 1.0. NOAA Center for Weather and Climate Prediction, College Park, MD, 73 pp. [Available online at www.ospo.noaa.gov/ Products/atmosphere/soundings/nucaps/docs/ NUCAPS ATBD 20130821.pdf.]

, and C. D. Barnet, 2013: Methodology and information content of the NOAA NESDIS operational channel selection for the Cross-Track Infrared Sounder (CrIS). IEEE Trans. Geosci. Remote Sens., 51, 3207-3216, Crossref.

, N. R. Nalli, C. D. Barnet, C. Tan, F. Iturbide-Sanchez, and K. Zhang, 2017: The NOAA Unique Combined Atmospheric Processing System (NUCAPS): Algorithm theoretical basis document, version 2.0. NOAA/NESDIS Center for Satellite Applications and Research and NOAA Center for Weather and Climate Prediction, College Park, MD, 84 pp. [Available online at www.star. nesdis.noaa.gov/jpss/documents/ATBD/ATBD NUCAPS v2.0.pdf.]

Kidder, S. Q., M. D. Goldberg, R. M. Zehr, M. DeMaria, J. F. W. Purdom, C. S. Velden, N. C. Grody, and S. J. Kusselson, 2000: Satellite analysis of tropical cyclones using the Advanced Microwave Sounding Unit (AMSU). Bull. Amer. Meteor. Soc., 81, 1241-1260, Crossref.

Lacagnina, M., 2010: Snowballs in the fuel system. AeroSafety WORLD , 5, 20-23. [Available online at flightsafety.org/ asw/feb10/asw_feb10_p20-23.pdf.] 
Likert, R., 1932: A technique for the measurement of attitudes. Archives of Psychology, 22, 5-55. [Available online at legacy.voteview.com/pdf/Likert 1932.pdf.]

Malmquist, S., 2014: "Cold Fuel." Air Transport Safety Articles (blog), April 3, 2013. [Available online at 03/ cold-fuel/.]

Nalli, N. R., and Co-authors, 2013: Validation of satellite sounder environmental data records: Applications to the Cross-track Infrared Microwave Sounder Suite. J. Geophys. Res.: Atmos., 118, 13,628-13,643, Crossref. , and Co-authors, 2017: Validation of atmospheric profile retrievals from the SNPP NOAA-Unique Combined Atmospheric Processing System. Part 1: Temperature and moisture. IEEE Trans. Geosci. Remote Sens., 56, 180-190, Crossref.

Sleight, P. A., and R. D. G. Carter, 2010: Report on the accident to Boeing 777-236ER, G-YMMM, at London Heathrow Airport on 17 January 2008. Air Accident Report 1/2010, Department for Transport, United Kingdom, 243 pp. [Available online at assets.publishing. service.gov.uk/media/5422f3dbe5274a1314000495/12010 G-YMMM.pdf.]

Smith, W. L., E. Weisz, S. V. Kireev, D. K. Zhou, Z. Li, and E. E. Borbas, 2012: Dual-regression retrieval algorithm for real-time processing of satellite ultraspectral radiances. J. Appl. Meteorol. Clim., 51, 1455-1476, Crossref.

Smith, N., K. D. White, E. Berndt, B. T. Zavodsky, A. Wheeler, M. A. Bowlan, and C. D. Barnet, 2018: NUCAPS in AWIPS: Rethinking information compression and distribution for fast decision making. Recorded presentation, 22nd Conf. on Satellite Meteorology and Oceanography, Austin, TX, Amer. Met. Soc., 6A.6. [Available online at ams.confex.com/ams/98Annual/ webprogram/Paper336846.html.]

, and Co-authors, 2015: Novel applications of temperature soundings in high latitude regions Aviation in Alaska. 20th International TOVS Study Conf., Lake Geneva, WI. International TOVS Working Group. [Available online at cimss.ssec.wisc.edu/itwg/ itsc/itsc 20/program/PDFs/290ct/session $4 \mathrm{~b} / 4 \mathrm{p} 04$ smith.pdf.]

SSEC, cited 2018: Polar2Grid (software). [Available online at software/polar2grid/.]

Susskind, J., C. D. Barnet, and J. M. Blaisdell, 2003: Retrieval of atmospheric and surface parameters from AIRS/ AMSU/HSB data in the presence of clouds. IEEE Trans. Geosci. Remote Sens., 41, 390-409, Crossref.

The Satellite Proving Ground at the Hazardous Weather Testbed, 2017: "NUCAPS for 0C and -20C levels." (Blog). [Available online at goesrhwt.blogspot. com/2017/06/nucaps-for-0c-and-20c-levels.html.]
The Satellite Proving Ground at the Hazardous Weather Testbed, 2018: "Simple WV RGB compared with NUCAPS." (Blog). [Available online at goesrhwt. blogspot.com/2018/05/simplewvrgb-perusing.html.]

Unidata, cited 2018: Local Data Manager (software). UCAR/ Unidata, Boulder, $\mathrm{CO}$, $\underline{\text { Crossref. }}$

Weaver, G. M., and Co-authors, 2018: Results from an operational demonstration of a gridded CrIS/ATMS product for cold air aloft. Recorded presentation, 22nd Conf. on Satellite Meteorology and Oceanography, Austin, TX, Amer. Meteor. Soc., 6A.4. [Available online at ams.confex.com/ams/98Annual/webprogram/ Paper323132.html.]

Weisz, E., W. L. Smith, and N. Smith, 2013: Advances in simultaneous atmospheric profile and cloud parameter regression based retrieval from high-spectral resolution radiance measurements. J. Geophys. Res.: Atmos., 118, 6433-6443, Crossref.

, N. Smith, and W. Smith Sr., 2014: Encouraging the use of hyperspectral sounder products in forecasting applications. 4th Conf. on Transition of Research to Operations, Atlanta, GA, Amer. Meteor. Soc., 3.3. [Available online at ams.confex.com/ams/94Annual/ webprogram/Paper241469.html.]

Werner, D., 2018: Danger in the air. Aerospace America, 56, 30-34. [Available online at aerospaceamerica.aiaa. org/features/danger-in-the-air/.]

Zavodsky, B. T., A. L. Molthan, and M. J. Folmer, 2013: Multispectral imagery for detecting stratospheric air intrusions associated with mid-latitude cyclones. $J$. Operational Meteor., 1, 71-83, Crossref.

, and Co-authors, 2016: Development and evaluation of a gridded CrIS/ATMS visualization for operational forecasting, 2016 American Geophysical Union Fall Meeting, San Francisco, CA, IN31A-1734. [Available online at Paper/138263.]

, and Co-authors, 2017: A Gridded CrIS/ATMS visualization for operational forecasting, 28th Conf. on Weather Analysis and Forecasting/24th Conf. on Numerical Weather Prediction, Seattle, WA. Amer. Meteor. Soc., 7A.2. [Available online at ams.confex. com/ams/97Annual/webprogram/Paper313854.html.] 